\title{
Is a 'guideline-compliant' primary cesarean delivery associated with a modified risk for maternal and neonatal morbidity?: a clinical evaluation of the 2014 ACOG/SMFM obstetric care consensus statement
}

\author{
Andrew W. White' ${ }^{1}$ Charis N. Chambers ${ }^{2}$, Michelle C. Ertel ${ }^{3}$, Taylor R. Gennaro ${ }^{4}$, Ling Chen ${ }^{5}$, \\ Alexander M. Friedman ${ }^{6}$ and Kacey Y. Eichelberger ${ }^{7^{*}}$ (D)
}

\begin{abstract}
Background: It is currently unknown whether primary CDs performed in compliance with the 2014 ACOG/SMFM Obstetric Care Consensus Statement guidelines ("guideline-compliant") are associated with a modified risk of maternal and neonatal morbidity, when compared to primary CDs performed outside the guidelines ("guidelinenoncompliant"). Our primary objective was to determine if a guideline-compliant primary CD is associated with a modified risk for maternal or neonatal morbidity, when compared to guideline-noncompliant primary CD.

Methods: A retrospective cohort study of all primary CDs at one tertiary referral center in the calendar year following publication of the Consensus Statement. Logistic regression was performed to calculate the risk of adverse maternal and neonatal outcomes for guideline-compliant primary CDs, when compared to guidelinenoncompliant and guideline-not addressed, and when adjusted for maternal age, BMI, hypertension, gestational age at delivery, insurance carrier, and provider practice.

Results: Eight hundred twenty-seven primary CDs were included during the study period, of which 34.8, 26.0, and 39.2\% were guideline compliant, guideline-noncompliant, and guideline-not addressed. No statistically significant differences in the frequency of adverse maternal outcomes across these three groups were observed with the exception of maternal ICU admission, which was significantly associated with a guideline-not addressed primary CD $(p=0.0002)$. No statistical difference in rates of $\mathrm{NICU}$ admissions, 5 min APGAR $<5$, or umbilical artery cord $\mathrm{pH}<7$ were observed between guideline-compliant and guideline-noncompliant primary CDs.
\end{abstract}

Conclusion: Women undergoing guideline-compliant primary CDs were not significantly more likely to experience a maternal or neonatal morbidity when compared to guideline-noncompliant primary CDs.

Keywords: Cesarean delivery, Maternal morbidity, Neonatal morbidity, Guidelines

\footnotetext{
* Correspondence: kacey.eichelberger@prismahealth.org

Division of Mater nal-Fetal Medicine, Department of Obstetrics and Gynecology, Prisma Health Upstate/University of South Carolina School of Medicine Greenville, 890 West Faris Road, Suite 470, Greenville, SC 29605, USA

Full list of author information is available at the end of the article
}

C C The Author(s). 2021 Open Access This article is licensed under a Creative Commons Attribution 4.0 International License, which permits use, sharing, adaptation, distribution and reproduction in any medium or format, as long as you give appropriate credit to the original author(s) and the source, provide a link to the Creative Commons licence, and indicate if changes were made. The images or other third party material in this article are included in the article's Creative Commons licence, unless indicated otherwise in a credit line to the material. If material is not included in the article's Creative Commons licence and your intended use is not permitted by statutory regulation or exceeds the permitted use, you will need to obtain permission directly from the copyright holder. To view a copy of this licence, visit http://creativecommons.org/licenses/by/4.0/. The Creative Commons Public Domain Dedication waiver (http://creativecommons.org/publicdomain/zero/1.0/) applies to the data made available in this article, unless otherwise stated in a credit line to the data. 


\section{Background}

From 1996 to 2009 the rate of cesarean delivery (CD) in the United States increased from 20.7 to $32.9 \%$, and has since plateaued at $31.9 \%$ in 2018 [1]. While life-saving in many cases, $\mathrm{CD}$ is associated with an increase in maternal morbidity, maternal mortality, and neonatal morbidity, when compared to vaginal delivery (VD) [2]. A history of $\mathrm{CD}$ is associated with increased risk for future $\mathrm{CD}$, and increased morbidity in subsequent pregnancies [3].

The ideal CD rate to minimize maternal and neonatal morbidity and mortality is not well established. In 2014, both the American College of Obstetricians and Gynecologists (ACOG) and the Society for Maternal Fetal Medicine (SMFM) issued a national call to reduce the primary CD rate, codified in the Obstetric Care Consensus Statement, "Safe Prevention of the Primary Cesarean Delivery." [3] In this joint document, these national organizations outlined clear and specific recommendations for the management of the following, each of which are linked to a common indication for primary CD: first and second stages of labor, fetal heart rate monitoring, induction of labor, fetal malpresentation, suspected fetal macrosomia, excessive maternal weight gain, and twin gestations. Evidence suggests compliance with these recommendations in clinical practice is associated with a reduction in the primary $C D$ rate [4].

With any introduction of clinical care guidelines, ongoing evaluation of actual clinical outcomes is critical to determine (a) if implementation of the guidelines in 'real life' settings results in the outcome intended, and (b) to determine if compliance with the guidelines is associated with any unanticipated adverse outcomes. For example, ACOG had advocated for a reduction in non-medically indicated early-term deliveries for more than 10 years, a policy recommendation frequently referred to as "the 39 week rule." $[5,6]$ While implementation of this recommendation has been positively associated with a reduction in both total number of early term deliveries and neonatal morbidity [7], some data support an unanticipated increased risk of stillbirth at term $[8,9]$.

It is currently unknown whether primary CDs performed in compliance with the 2014 Obstetric Care Consensus Statement guidelines ("guideline-compliant") are associated with a modified risk of maternal and neonatal morbidity, when compared to primary CDs performed outside the new guidelines ("guideline-noncompliant"). Our primary objective was to determine if a guidelinecompliant primary CD is associated with a modified risk for maternal or neonatal morbidity, when compared to guideline-noncompliant primary $\mathrm{CD}$. We hypothesized that guideline-compliant CDs are associated with increased maternal morbidity, when compared to guidelinenoncompliant primary CDs, as guideline-compliant CDs for failed induction of labor or arrest of the first or second stages are associated with a longer window from admission-to-delivery.

\section{Methods}

This retrospective cohort study included all women undergoing primary $\mathrm{CD}$ at a single tertiary referral center between January 1 and December 31, 2015, the first full calendar year following publication of the Obstetric Care Consensus Statement guidelines. During the previous year, our department embarked on substantial quality improvement (QI) work around the Consensus Statement, which included educational sessions for all delivery providers and labor unit nurses, simulation work, and the public posting of the guidelines on all Labor and Delivery units. While compliance with the guidelines was not formally enforced, it was strongly encouraged and modeled by physician and nursing leadership in a continuous QI process.

Eligible subjects were identified by a query of SoftMed for the ICD-9 code 654.21 and the ICD-10 code 03421 (primary CD). The total number of women delivering in the same time period without a history of prior CD was also identified by a SoftMed query; this number was used to calculate primary $C D$ rates (defined as the number of women delivering via primary $C D$ in a given time frame divided by the number of women delivering during the same time frame without a prior CD).

Basic demographic data was collected including maternal age, race/ethnicity, insurance payer and marital status. Clinical covariates of interest included BMI $(\mathrm{kg} / \mathrm{m} 2$ at initiation of prenatal care), parity, gestational age at delivery, single versus multiple gestations, and labor status on admission (spontaneous, induced, augmented, or none). Presence of the three most prevalent medical comorbidities in our patient population was evaluated: smoking status, hypertension and diabetes mellitus. Variables were collected from manual chart review from the electronic medical records systems used at our institution during the study period, which include Soarian, Centricity Perinatal, Sovera, and Epic.

The indication for a primary CD was identified from reviewing the operative report, the archived labor notes, and any additional clinical documentation. This detailed chart review was performed by one of two physician investigators (AW, $\mathrm{CC}$ ). Each primary $\mathrm{CD}$ was then classified into one of three study groups ("guidelinecompliant," "guideline-noncompliant," or "guideline-not addressed") by comparing provider and/or labor nurse documentation to a standard rubric crafted from the 2014 Obstetric Care Consensus Statement, "Safe Prevention of the Primary Cesarean Delivery" (Table 1) [3]. Complex cases were adjudicated by a single senior investigator (KE) at our institution. 
Table 1 Guidelines for "compliant" cesarean deliveries

\begin{tabular}{|c|c|}
\hline $\begin{array}{l}\text { Failed induction of } \\
\text { labor }\end{array}$ & $\begin{array}{l}\text { Latent phase persists despite: } \\
\text { - Cervical ripening for Bishops score } \leq 6 \mathrm{~cm} \\
\text { - At least } 24 \mathrm{~h} \text { in the latent phase (defined as } \\
\text { from initiation of cervical ripening, pitocin } \\
\text { started, or AROM [whichever came first] to } \\
\text { time of delivery) } \\
\text { - At least } 12 \mathrm{~h} \text { of pitocin after rupture of } \\
\text { membranes }\end{array}$ \\
\hline $\begin{array}{l}\text { Arrest of the first } \\
\text { stage of labor }\end{array}$ & $\begin{array}{l}\text { Cervix } \geq 6 \mathrm{~cm} \text { and ruptured membranes with: } \\
\text { - No cervical change despite } 4 \mathrm{~h} \text { of adequate } \\
\text { uterine contractions with IUPC and MVU > } \\
200 \\
\text { Or } \\
\text { - No cervical change despite } 6 \mathrm{~h} \text { of } \\
\text { inadequate uterine contractions with or } \\
\text { without IUPC }\end{array}$ \\
\hline $\begin{array}{l}\text { Arrest of the second } \\
\text { stage of labor }\end{array}$ & $\begin{array}{l}\text { - Operative VD attempted for arrest and } \\
\text { unsuccessful } \\
\text { Or } \\
\text { - At least } 2 \mathrm{~h} \text { of pushing in multiparous } \\
\text { women } \\
\text { Or } \\
\text { - At least } 3 \mathrm{~h} \text { of pushing in nulliparous women } \\
\text { And } \\
\text { - If vertex is documented as malpositioned, } \\
\text { manual rotation of fetal occiput must be } \\
\text { attempted (only compliant for } \mathrm{c} / \mathrm{s} \text { if also } \\
\text { pushed for the above durations) }\end{array}$ \\
\hline Macrosomia & $\begin{array}{l}\text { - Ultrasound estimated fetal weight } \geq 4500 \mathrm{~g} \\
\text { in women with diabetes } \\
\text { Or } \\
\text { - Ultrasound estimated fetal weight } \geq 5000 \mathrm{~g} \\
\text { in women without diabetes }\end{array}$ \\
\hline Malpresentation & $\begin{array}{l}\text { - External cephalic version attempted and } \\
\text { failed } \\
\text { Or } \\
\text { - External cephalic version counseling } \\
\text { documented and declined }\end{array}$ \\
\hline Twin gestations & $\begin{array}{l}\text { - Presenting twin is cephalic and patient } \\
\text { counseled toward VD but opted for CD } \\
\text { Or } \\
\text { - Presenting twin is non-cephalic }\end{array}$ \\
\hline $\begin{array}{l}\text { Non-reassuring fetal } \\
\text { heart tones }\end{array}$ & $\begin{array}{l}\text { - Amnioinfusion prior to CD in the setting of } \\
\text { variable decelerations } \\
\text { And/Or } \\
\text { - Scalp stimulation documented prior to CD in } \\
\text { the setting of minimal or absent variability }\end{array}$ \\
\hline
\end{tabular}

Based on the ACOG/SMFM 2014 Obstetric Care Consensus Statement, "Safe Prevention of the Primary Cesarean Delivery" [3]

Adverse maternal outcomes included: chorioamnionitis; postpartum hemorrhage, defined as an estimated blood loss > $1000 \mathrm{~mL}$ [10]; maternal infectious complications (superficial surgical site infection [involvement of skin or subcutaneous tissue] [11], deep incisional surgical site infection [involvement of fascia and muscle] [11], organ/space surgical site infection [11], endometritis, urinary tract infection, or pneumonia); surgical complications (hysterectomy, broad ligament hematoma, cystotomy [requiring repair], ureteral injury, bowel injury [requiring repair]); reoperation; and transfusion of packed red blood cells. Adverse neonatal outcomes included NICU admission, 5 min Apgar $\leq 5$, umbilical artery cord gas $\mathrm{pH} \leq 7$, and neonatal death.

Statistical analysis was performed with SAS Statistical Software (Cary, North Carolina). Chi squared and Fisher's exact test were used for categorical data, where appropriate, and t-tests were used for continuous variables. Logistic regression was performed to calculate the risk of adverse maternal and neonatal outcomes for guideline-compliant primary $\mathrm{CDs}$, when compared to guideline-noncompliant and guideline-not addressed, and when adjusted for maternal age, BMI, hypertension, gestational age at delivery, insurance carrier, and provider practice. A two-sided $p$ value $<0.05$ was considered statistically significant. This study conforms to STROBE guidelines for cohort studies.

\section{Results}

Our final cohort included 827 women who delivered via primary $C D$ during the study period. During the same period, 4938 women delivered without a history of prior $\mathrm{CD}$, for a total institutional primary CD rate of $16.7 \%$. Of our total primary CD cohort, 288 (34.8\%) were determined to be guideline-compliant, 215 (26.0\%) were guideline-noncompliant, and 324 (39.2\%) were guidelinenot addressed.

Baseline demographics of these three study groups are listed in Table 2. Statistically significant differences identified between the study groups include maternal parity, gestational age at delivery, labor status, and number of fetuses.

Based on the 2014 Guidelines, indications for primary CD were divided into six categories (Table 1). During the study period, labor arrest (including failed induction and arrests of the first and second stages of labor) was the most common indication for primary $\mathrm{CD}$, followed by (in order): non-reassuring fetal tracing; malpresentation; "other" (which included: prior myomectomy, placenta/vasa previa, cord prolapse, maternal infections [HIV with viral load $>1000$ or active HSV], presumed fetal intolerance of labor, prior 3rd or 4th degree perineal laceration, prior shoulder dystocia, fetal anomaly, maternal request, maternal condition, or fetal condition); multiple gestations; and macrosomia.

The frequency of adverse maternal outcomes associated with guideline-compliant versus guideline-noncompliant and guideline-not addressed primary CDs are shown in Table 3. There were no statistically significant differences in the frequency of adverse maternal outcomes across these three groups with the exception of maternal ICU admission, which was significantly associated with a guideline-not addressed primary CD $(p=0.0002)$.

Adverse neonatal outcomes associated with primary CD during the study period are presented in Table 4 . The risk of neonatal death, low $\mathrm{pH}<7$, and $\mathrm{NICU}$ 
Table 2 Baseline demographics

\begin{tabular}{|c|c|c|c|c|c|c|}
\hline & \multicolumn{2}{|c|}{ Compliant } & \multicolumn{2}{|c|}{ Non-compliant } & \multicolumn{2}{|c|}{ Not addressed } \\
\hline & $\mathbf{N}$ & (\%) & $\mathrm{N}$ & (\%) & $\mathrm{N}$ & (\%) \\
\hline All & 288 & $(34.8)$ & 215 & $(26.0)$ & 324 & (39.2) \\
\hline \multicolumn{7}{|c|}{ Maternal age } \\
\hline $14-17$ & 3 & (1.0) & 4 & (1.9) & 7 & $(2.2)$ \\
\hline $18-24$ & 84 & $(29.2)$ & 49 & $(22.8)$ & 82 & (25.3) \\
\hline $25-29$ & 85 & (29.5) & 63 & (29.3) & 78 & $(24.1)$ \\
\hline $30-34$ & 75 & (26.0) & 70 & (32.6) & 92 & $(28.4)$ \\
\hline $35-39$ & 30 & $(10.4)$ & 25 & (11.6) & 42 & (13.0) \\
\hline$>39$ & 11 & (3.8) & 4 & $(1.9)$ & 23 & $(7.1)$ \\
\hline
\end{tabular}

\section{Race/Ethnicity}

$\begin{array}{llll}\text { Asian } & 5 & (1.7) & 6 \\ \text { Black } & 61 & (21.2) & 31 \\ \text { White } & 193 & (67.0) & 151 \\ \text { Hispanic } & 24 & (8.3) & 24 \\ \text { Other/unknown } & 5 & (1.7) & 3\end{array}$

\section{Payer}

$\begin{array}{llll}\text { Commercial } & 156 & (54.2) & 151 \\ \text { Medicaid } & 129 & (44.8) & 57 \\ \text { Medicare } & 0 & (0.0) & 1 \\ \text { Self pay } & 0 & (0.0) & 2 \\ \text { Other } & 3 & (1.0) & 4\end{array}$

\section{Marital status}

Married
Not married
Unknown

$p$-value

BMI

$$
\begin{aligned}
& <20 \\
& 20-<25 \\
& 25-<30 \\
& 30-<35 \\
& >1=35
\end{aligned}
$$

Para

$\begin{array}{ll}0 & 227 \\ 1 & 35 \\ >1 & 26\end{array}$

Gestational age

$$
<32
$$

8

32 to $<37$

37 to $<39$

39 to $<41$

$>/=41$

14
70
83
61
60

(4.9)

(24.3)

(28.8)

(21.2)

(20.8)

(78.8)

(12.2)

(9.0)

(2.8)

(9.4)

(25.3)

(46.2)

(16.3)

(8.0)

(37.8)

\begin{abstract}
Augmented
Induced
\end{abstract}

23

109
133

47

政


Table 2 Baseline demographics (Continued)

\begin{tabular}{|c|c|c|c|c|c|c|c|}
\hline & \multicolumn{2}{|c|}{ Compliant } & \multicolumn{2}{|c|}{ Non-compliant } & \multicolumn{2}{|c|}{ Not addressed } & \multirow[b]{2}{*}{$p$-value } \\
\hline & $N$ & $(\%)$ & $\mathrm{N}$ & (\%) & $\mathrm{N}$ & (\%) & \\
\hline Spontaneous & 69 & $(24.0)$ & 40 & (18.6) & 77 & (23.8) & \\
\hline None & 87 & $(30.2)$ & 44 & (20.5) & 156 & $(48.1)$ & \\
\hline
\end{tabular}

admission was significantly higher with guideline-not addressed primary $\mathrm{CD}$, when compared to guidelinecompliant and guideline-noncompliant primary CDs $(p=0.009, \quad 0.021$, and $<0.001$, respectively). When guideline-not addressed primary CDs were excluded from the analysis, there was no statistical difference in rates of NICU admissions, 5 min APGAR $<5$, or umbilical artery cord $\mathrm{pH}<7$ between guideline-compliant and guideline-noncompliant primary CDs.

In logistic regression analyses, women undergoing guideline-compliant primary $\mathrm{CD}$ were no more likely to experience an adverse maternal outcome when compared to guideline-noncompliant and guideline-not addressed primary CDs. This remained true when adjusted for maternal parity, gestational age at delivery, labor status, and number of fetuses (AOR 1.10, 95\% CI 0.582.07; AOR 1.20, 95\%CI 0.67-2.14, respectively). However, guideline not-addressed primary $\mathrm{CDs}$ were associated with a significantly increased risk of any adverse maternal or neonatal outcomes, when compared to guideline-compliant primary CDs and when adjusted for maternal parity, gestational age at delivery, labor status, and number of fetuses (AOR 4.16, 95\% CI 2.78-6.23).

Finally, a sensitivity analysis was performed for the logistic regression model including any maternal or neonatal morbidity but restricted to births $\geq 37$ weeks. Guideline-not addressed primary CDs remained significantly associated with an increased but attenuated risk for either maternal or neonatal morbidity when compared to guideline-compliant primary CDs (AOR1.95, 95\% CI 1.18-3.22).

\section{Discussion}

This quality improvement work suggests that over the course of 1 year at a tertiary referral center, women undergoing guideline-compliant primary $\mathrm{CDs}$ were not

Table 3 Maternal outcomes

\begin{tabular}{|c|c|c|c|c|c|c|c|}
\hline & \multicolumn{2}{|c|}{ Compliant } & \multicolumn{2}{|c|}{ Noncompliant } & \multicolumn{2}{|c|}{ Not addressed } & \multirow[b]{2}{*}{$p$-value } \\
\hline & $\bar{N}$ & (\%) & $\bar{N}$ & (\%) & $\mathrm{N}$ & (\%) & \\
\hline All patients & 288 & $(34.8)$ & 215 & $(26.0)$ & 324 & $(39.2)$ & \\
\hline \multicolumn{8}{|l|}{ Maternal outcomes } \\
\hline Maternal death & 0 & $0.00 \%$ & 0 & $0.00 \%$ & 1 & $0.31 \%$ & 0.46 \\
\hline VTE & 1 & $0.35 \%$ & 0 & $0.00 \%$ & 2 & $0.62 \%$ & 0.51 \\
\hline ICU admission & 0 & $0.00 \%$ & 0 & $0.00 \%$ & 11 & $3.40 \%$ & 0.0002 \\
\hline Transfusion & 11 & $3.82 \%$ & 5 & $2.33 \%$ & 21 & $6.48 \%$ & 0.06 \\
\hline $\mathrm{PPH}$ & 7 & $2.43 \%$ & 10 & $4.65 \%$ & 13 & $4.01 \%$ & 0.38 \\
\hline \multicolumn{8}{|l|}{ Surgical complication } \\
\hline Reoperation & 1 & $0.35 \%$ & 1 & $0.47 \%$ & 2 & $0.62 \%$ & 0.89 \\
\hline Bowel injury & 0 & $0.00 \%$ & 0 & $0.00 \%$ & 1 & $0.31 \%$ & 0.46 \\
\hline Ureteral injury & 0 & $0.00 \%$ & 0 & $0.00 \%$ & 0 & $0.00 \%$ & N/A \\
\hline Cystotomy & 0 & $0.00 \%$ & 1 & $0.47 \%$ & 0 & $0.00 \%$ & 0.24 \\
\hline Broad ligament hematoma & 0 & $0.00 \%$ & 1 & $0.47 \%$ & 1 & $0.31 \%$ & 0.55 \\
\hline Hysterectomy & 0 & $0.00 \%$ & 0 & $0.00 \%$ & 3 & $0.93 \%$ & 0.10 \\
\hline \multicolumn{8}{|l|}{ Maternal infections } \\
\hline Pneumonia & 0 & $0.00 \%$ & 0 & $0.00 \%$ & 1 & $0.31 \%$ & 0.46 \\
\hline Urinary tract infection & 2 & $0.69 \%$ & 0 & $0.00 \%$ & 2 & $0.62 \%$ & 0.49 \\
\hline Endometritis & 8 & $2.78 \%$ & 4 & $1.86 \%$ & 4 & $1.23 \%$ & 0.38 \\
\hline Superficial SSI & 3 & $1.04 \%$ & 2 & $0.93 \%$ & 3 & $0.93 \%$ & 0.99 \\
\hline Deep incisional SSI & 0 & $0.00 \%$ & 1 & $0.47 \%$ & 0 & $0.00 \%$ & 0.24 \\
\hline Organ/space SSI & 0 & $0.00 \%$ & 0 & $0.00 \%$ & 0 & $0.00 \%$ & N/A \\
\hline
\end{tabular}


Table 4 Neonatal outcomes

\begin{tabular}{|c|c|c|c|c|c|c|c|}
\hline & \multicolumn{2}{|c|}{ Compliant } & \multicolumn{2}{|c|}{ Noncompliant } & \multicolumn{2}{|c|}{ Not addressed } & \multirow[b]{2}{*}{$p$-value } \\
\hline & $\mathrm{N}$ & (\%) & $\mathrm{N}$ & $(\%)$ & $\mathbf{N}$ & (\%) & \\
\hline All patients & 288 & (34.8) & 215 & $(26.0)$ & 324 & (39.2) & \\
\hline \multicolumn{8}{|c|}{ Neonatal outcomes } \\
\hline NICU admission & 51 & $17.71 \%$ & 27 & $12.56 \%$ & 148 & $45.68 \%$ & $<0.0001$ \\
\hline Low Apgar $(\leq 5)$ & 11 & $3.82 \%$ & 5 & $2.33 \%$ & 21 & $6.48 \%$ & 0.06 \\
\hline Low pH ( $\leq 7)$ & 3 & $1.04 \%$ & 1 & $0.47 \%$ & 11 & $3.40 \%$ & 0.02 \\
\hline Neonatal death & 0 & $0.00 \%$ & 0 & $0.00 \%$ & 9 & $2.78 \%$ & 0.0009 \\
\hline
\end{tabular}

significantly more likely to experience a maternal or neonatal morbidity when compared to guidelinenoncompliant primary CDs. Therefore, it is plausible that compliance with the guidelines recommended in the ACOG/SMFM 2014 Obstetric Care Consensus Statement, "Safe Prevention of the Primary Cesarean Delivery" [3] may be associated with a decreased primary $C D$ rate without an increased risk of adverse maternal or neonatal outcomes. This hypothesis should be tested in larger cohorts, as we were underpowered to detect small differences in more rare outcomes given our fixed sample size. In post hoc analysis, we estimate that a future cohort would need a sample size of 14,160 primary CDs to detect a significant difference in frequency of transfusion (the most prevalent adverse maternal outcome in our study) between guideline-compliant and guidelinenoncompliant primary CDs, if one exists.

This work represents the sum of a year-long Quality Improvement (QI) initiative in our large academic medical center. After the publication of the 2014 Consensus Statement, we conducted multiple educational sessions for all delivery providers and nurses on the topic and posted the new rubric in highly visible locations on our Labor and Delivery units. While individual obstetric providers were not formally required to follow the guidelines (as evidenced by a $26 \%$ rate of guideline noncompliance), there was strong cultural and institutional influence to follow the new guidelines. After so much intentional focus on guideline compliance versus noncompliance, a very unexpected finding was that the largest percentage of our cohort (39\%) underwent guideline-not addressed primary $\mathrm{CD}$. Therefore, the $\mathrm{Ob}-$ stetric Care Consensus Statement recommendations, at most, only apply to $61 \%$ of our study population. We hypothesize that the higher rates of any maternal or neonatal adverse outcome associated with guideline-not addressed primary CDs when compared to guidelinecompliant or guideline-noncompliant may be attributable to confounding by indication, as many of these women had indications for due to confounding by indication; indeed for many of those cases, it was the indication for $\mathrm{CD}$ that predisposed them to maternal ICU admission, NICU admission, or low 5 min APGAR, not the CD itself.

Strengths of our study include that this was the first clinical evaluation of primary CD morbidity following publication of the ACOG/SMFM 2014 Obstetric Care Consensus Statement, "Safe Prevention of the Primary Cesarean Delivery," [3] a critical step after implementation of any new clinical care guidelines in real practice settings. Furthermore, data on clinical practice and decision-making (eg, number of hours spent in each labor phase and stage, number of hours exposed to oxytocin, whether or not external cephalic version was offered) were collected by one of two physicians in granular detail after thorough chart review. This quality of data cannot be easily extracted from databases alone and represents a unique strength of our approach. This hypothesis generating work should be replicated in larger longitudinal cohorts to better define excess risk associated with guideline compliance, if any exists.

A weakness of this study is that it was performed at a single tertiary referral institution as part of internal QI work, and the sample size was inherently limited by delivery volume over that 12 month study window. As this was a pragmatic QI design and formal sample size analysis was not done a priori, we were underpowered to detect small differences in rare outcomes. That said, our data are hypothesis generating and can inform power calculations for future investigations on this topic. Furthermore, while we controlled for the three most common comorbidities in our population (hypertension, diabetes, and smoking), it is possible other maternal medical comorbidities impact the association between guideline compliance and either maternal or neonatal outcomes. We were also unable to quantify the impact of delivery provider type (physician versus midwife) on compliance with ACOG guidelines given the small number of midwifery providers in our sample.

\section{Conclusion}

Providers and institutions have done meaningful work to safely reduce the rate of CD in the US, including systematic approaches to scaling the ACOG/SMFM 2014 
Obstetric Care Consensus Statement, "Safe Prevention of the Primary Cesarean Delivery, and the Council on Patient Safety in Women's Health Care's "Patient Safety Bundle on the Safe Reduction of Primary Cesarean Births" across multiple sites [12-14]. That said, the primary outcome for this sort of work is usually, and predictably, the rate of $\mathrm{CD}$. While reducing that absolute rate is important, we must remain mindful of the larger goal: the lowest possible rate of aggregate maternal and neonatal morbidity. For our patients' safety, critically analyzing the downstream consequences of nationally recommended safety bundles and obstetric care consensus statements will be as important as our analysis of their primary efficacy.

\section{Abbreviations}

ACOG: American College of Obstetricians and Gynecologists; SMFM: Society for Maternal Fetal Medicine; CD: Cesarean delivery; ICU: Intensive care unit; NICU: Neonatal intensive care unit

\section{Acknowledgements}

None.

\section{Authors' contributions}

All authors except $C L$ were involved in the study design. AW, CC, TG, ME, and $K E$ were involved in data collection. $C L$ and AF performed data analysis. AW, ME, KE, and AF edited the manuscript. All authors approved the manuscript.

\section{Funding}

Not applicable.

\section{Availability of data and materials}

The datasets used and/or analysed during the current study are available from the corresponding author on reasonable request.

\section{Declarations}

Ethics approval and consent to participate

This study was approved by the Greenville Health System IRB (Pro00057229).

\section{Consent for publication}

Not applicable.

\section{Competing interests}

Not applicable.

\section{Author details}

'Department of Obstetrics and Gynecology, Prisma Health Upstate/University of South Carolina School of Medicine Greenville, West Faris Road, Suite 470, Greenville, SC 29605, USA. ${ }^{2}$ Division of Pediatric and Adolescent Gynecology, Department of Obstetrics and Gynecology, Baylor University, 1 Baylor Plaza, Houston, TX 77030, USA. ${ }^{3}$ Department of Obstetrics and Gynecology, University of North Carolina Chapel Hill, 3009 Old Clinic Building CB 7570, Chapel Hill, NC 27599, USA. ${ }^{4}$ University of South Carolina School of Medicine, 6311 Garners Ferry Road, Columbia, SC 29209, USA. ${ }^{5}$ Department of Obstetrics and Gynecology, Columbia University, 622 W 168th St, New York, NY 10032, USA. 'Division of Maternal-Fetal Medicine, Department of Obstetrics and Gynecology, Columbia University, 622 W 168th St, New York, NY 10032, USA. 'Division of Mater nal-Fetal Medicine, Department of Obstetrics and Gynecology, Prisma Health Upstate/University of South Carolina School of Medicine Greenville, 890 West Faris Road, Suite 470, Greenville, SC 29605, USA.
Received: 22 April 2020 Accepted: 12 August 2021

Published online: 22 August 2021

\section{References}

1. CDC National Vital Statistics System, Key Birth Statistics. Births: Final Data for 2018. https://www.cdc.gov/nchs/nvss/births.htm. Date accessed 10 Jan 2020

2. Clark SL, Belfort MA, Dildy GA, Herbst MA, Meyers JA, Hankins GD. Maternal death in the 21st century: causes, prevention, and relationship to cesarean delivery. AJOG. 2008;199:36.e1-5.

3. Safe prevention of the primary cesarean delivery. Obstetric care consensus no. 1. American College of Obstetricians and Gynecologists. Obstet Gynecol. 2014;123(3):693-711. https://doi.org/10.1097/01.AOG.0000444441.04111.1d.

4. Wilson-Leedy JG, DiSilvestro AJ, Repke JT, Pauli JM. Reduction in the cesarean delivery rate after obstetric care consensus guideline implementation. Obstet Gyencol. 2016;128(1):145-52. https://doi.org/10.1 097/AOG.0000000000001488.

5. Nonmedically indicated early-term deliveries. Committee opinion no. 561. American College of Obstetricians and Gynecologists. Obstet Gynecol. 2013; 121(4):911-5. https://doi.org/10.1097/01.AOG.0000428649.57622.a7.

6. Oshiro BT, Henry E, Wilson J, Branch DW, Varner MW, Women and Newborn Clinical Integration Program. Decreasing elective deliveries before 39 weeks of gestation in an integrated health care system. Obstet Gynecol. 2009; 113(4):804-11. https://doi.org/10.1097/AOG.0b013e31819b5c8c.

7. Ehrenthal DB, Hoffman MK, Jiang X, Ostrum G. Neonatal outcomes after implementation of guidelines limiting elective delivery before 39 weeks of gestation. Obstet Gynecol. 2011;118(5):1047-55. https://doi.org/10.1097/A OG.0b013e3182319c58.

8. Nicholson JM, Kellar LC, Ahmad S, Abid A, Woloski J, Hewamudalige N, et al. US term stillbirth rates and the 39-week rule: a cause for concern? Am J Obstet Gynecol. 2016;214:621.e1-9.

9. Little SE, Zera CA, Clapp MA, Wilkins-Haug L, Robinson JN. A multi-state analysis of early-term delivery trends and the association with term stillbirth. Obstet Gynecol. 2015;126(6):1138-45.

10. Postpartum hemorrhage. ACOG practice bulletin no. 76. American College of Obstetricians and Gynecologists. Obstet Gynecol. 2006;108(4):1039-47. https://doi.org/10.1097/00006250-200610000-00046.

11. Horan TC, Gaynes RP, Martone WJ, Jarvis WR, Emori TG. CDC definitions of nosocomial surgical site infections, 1992: a modification of CDC definitions of surgical wound infections. Infect Control Hosp Epidemiol. 1992;13(10): 606-8. https://doi.org/10.2307/30148464.

12. Bell $A D$, Joy $S$, Gullo $S$, Higgins R, Stevenson E. Implementing a systematic approach to reduce cesarean birth rates in nulliparous women. Obstet Gynecol. 2017;130(5):1082-9.

13. Agosta $\sqcup$, Johnson $C$. Implementing interventions aimed at reducing rates of cesarean birth. Nurs Womens Health. 2017:21(4):260-73.

14. Yu Y, Lin F, Dong W, Li H, Zhang X, Chen C. The effectiveness of financial intervention strategies for reducing caesarean section rates: a systematic review. BMC Public Health. 2019;19(1):1080. https://doi.org/10.1186/s12889019-7265-4

\section{Publisher's Note}

Springer Nature remains neutral with regard to jurisdictional claims in published maps and institutional affiliations.

\section{Ready to submit your research? Choose BMC and benefit from:}

- fast, convenient online submission

- thorough peer review by experienced researchers in your field

- rapid publication on acceptance

- support for research data, including large and complex data types

- gold Open Access which fosters wider collaboration and increased citations

- maximum visibility for your research: over $100 \mathrm{M}$ website views per year

At $\mathrm{BMC}$, research is always in progress.

Learn more biomedcentral.com/submission 